\title{
AS EMPRESAS EM SOCIEDADES CONTEMPORÂNEAS: a responsabilidade social no Norte e no Sul
}

\author{
PadaCappdin* \\ Raqua Giffoi ${ }^{* *}$
}

\section{INTRODUÇÃO}

Esteartigo recupera a trajetória do lema da ResponsabilidadeSocial, desdeasua introdução, em três contextos sociai s diferentes: no Norte (Estados Unidos deAmérica eUnião Européia) eno Sul (Brasil). O texto realizaumaanálisecomparativa, com o intuito de ajudar a explicitar as especificidades dos encaminhamentos adotados pelas empresas nessas diferentes sociedades. Também apresenta as iniciativas pionei ras eos recursos programáticos em três real idades sociopolíticas distintas, ao tempo em que procura desfazer a impressão dehomogenei dade que, muitas vezes, encobre a diversidade de sentidos e a gama de atribuições einiciativas no meio empresarial.

Para o filósofo P. Ricoeur (1994), o sentido daresponsabilidadedas instituições, alimentauma

* Professor-Doutor do Departamento de Sociologia e do Programa de Pós-Graduação em Sociologia e Antropologia da Universidade Federal do Rio de Janeiro ePesquisadora CNPq. Largo S. Francisco de Paula, n. 1. Rio de Janeiro - RJ - Brasil. cappellin@uol.com.br

** Aluna do Programa de Pós-Graduação em Sociologia e Antropol ogia da Universidade Federal do Rio de Janeiro. giffonipinto@yahoo.com.br relação. Conecta a preocupação de imputar (atribuir obrigações e limitações) a quem exerce um poder (econômico, como no caso aqui tratado) com o esforço deatribuir proteção a quemémais fraco. Podemos, assim, interrogar as empresas, averiguando de que forma incluem, em suas responsabilidades, as metas que a sociedade contemporânea Ihes atribui, como a produção de riqueza, o desenvolvimento eo emprego.

A literaturainternacional, desdeos meados dos anos 1970 (Hirschman, 1970; Sainsaulieu; Segrestin, 1986; Touraine, 1992; Castel, 1995) renova a preocupação em identificar a central idade da empresa no conjunto das modificações sociais. Essa "reabilitação da empresa no sistema social" (Borzeix, 1986, p.4) parecese conectar ao conjunto de alterações internas da própria sociedade, quando a economia eo emprego modificam suas contribuições para o desenvolvimento. Incluir, na perspectiva das responsabilidades, a meta institucional das políticas deemprego superaatradicional propostadaciência daadministração que, em geral, ao valorizar a autonomia da empresa, preocupa-secomsua performanceerentabilidade 
econômica. A empresa, ao ser chamada para “salvaguardar o emprego e, por extensão, para salvaguardar a sociedade" (Castel, 1995, p.518), envolve-seem diferentes processos deregulação, ganha um caráter institucional, é espaço social de ação col etiva, aptaa confrontar o discurso gerencial eas reivindicações. É com esse intuito que, para Sainsaulieu eSegrestin (1986), a sociologiadaempresa nasce fazendo frente "aos prejuízos tecnocráticos dasempresas" (Sainsaulieu; Segrestin, 1986 p.334). Também parao sociólogo Castel (1995, p.518), a estruturação recente do emprego, emsuas formas desubcontratações(flexi bilidadeexterna), e oenfrentamento denovassituações demercado (fle xibilidade interna) reabrem a discussão sobre "a função integradora da empresa”, já queessas práticas empresariaisaprofundamaseletividadepermanentedostrabal hadores. A estruturação do emprego decorre das escol has depolíticas detransformação e inovação tecnológi ca, aliadas a solicitações contínuas para modificar as exigências decompetências edequalificações. ${ }^{1}$

Apresentamos, mantendo a seqüênciahistórica, a introdução desse lema, primeiramente nos EUA, no decorrer da década de 1960; em seguida, a proliferação designificadosqueotemapassaaassumirno Brasil, a partir do final dos anos 1960; e, por fim, as convocatóriasnaUnião Européia, a partir de 1995. Nesses diversos contextos, o debate sobre a função social da empresa não emerge de forma homogênea e, menos ainda, ela é assumida publicamentecomo plataformaúnica. Acreditamosqueesse confronto internacional possaaumentar einovar as interrogações sobreossentidos deresponsabilidade das ações sociais das empresas no Brasil.

\section{DEMANDAS DE RESPONSABILIDADE SOCIAL ÀS CORPORAÇÕES: EUA nos anos 1960}

A dinâmica que levou, nos EUA, al gumas grandes corporaçõesa abandonarem seu isolamen-

${ }^{1}$ Castel chega a perguntar se hoje é possível “...tentar repensar se investir e ser competitiva para uma empresa deveria ser exclusivamente seguir políticas de comprimir ao máximo os custos sal ariais." (Castel, 1995, p.589) to do contexto social eajustarem suas metas eestratégias econômicas éreconhecida como questão nos anos 1960. Com efeito, diversos movimentos sociais, dentro efora do campo empresarial, contestaram a autonomia das corporações, gerando uma crise em relação à sua independência e seu autogoverno.

Nos EUA, durante as décadas de 1920 e 1930, o debatesobreo papel da corporação já dividia opiniões. É importanteter em menteque, nesse período, as duzentas maiores empresas, nos EUA, controlavam aproximadamente $50 \%$ da riqueza corporativa da nação e $22 \%$ da sua riqueza total (Berle; Mean, 1968).

O debatefoi retomado, seguindo-Kaufman, Zachariase Karson (1995), após aSegunda Guerra Mundial, quando houveum esforço legisl ativo de regulamentar as corporações. O livro de Howard R. Bowen, Social Responsibilities of the Businessman (1953), considerado uma das referências mais importantes nessetema, abreo caminho da reflexão sobre a responsabilidade social, formatando seu primeiro esboço: "Queresponsabilidades a empresa deveria assumir como próprias junto à sociedade?"2 Havia a crença de que as grandes empresas eram centros vitais de poder $\mathrm{e}$ detomada de decisão equesuas ações, em muitos pontos, afetavama vida dos cidadãos. Nos EUA, a sinergia quepermitiu a introdução do lema da responsabilidadesocial foi fomentada pelas pressões políticase pelas críticas públicas aos negócios das grandes corporações. Para D. Vogel a década de 1960 éo tempo em que, final mente, ... a corporação está sendo sujeita à mesma pres-
são democrática experimentada para a nação,
150 anos atrás. Assi m como o Estado democráti-
co, a corporação contemporânea deve agora se
ajustar continuamentea uma série de demandas
competitivas e conflitantes em relação aos seus
recursos (...) portanto, a gerência das corporações
éagora forçada a equil ibrar a demanda dos seus
acionistas, orientada para o lucro, com a necessi-
dade e demandas sociais e políticas feitas por
seus outros constituintes (Vogel, 1978, p.8-9).

${ }^{2}$ O sociól ogo americano Carroll (1999) define Bowen como o pai da responsabilidade social. 
Nos anos 1960 al gumas questões animaram o debate na sociedade americana: as reivindicações postas pel a ação da Era dos Direitos Civis; os movimentos durante a Guerra do Vietnã; o monitoramento real izado pelas I grejas Católicase Protestantes, no controle das empresas americanas no exterior; e, final mente, o esforço dos movimentos dosacionistas em politizar o gerenciamento das empresas. Esse conjunto de demandas e, ao mesmo tempo, a capacidade de mobilização de várias instituições revelam o quanto são amplos os interesses e quão diversificados são os "atores cidadãos" que se organizaram para monitorar o comportamento empresarial. Mas sugeretambém a evidência deumaampla rededeinfluências que propunham reverter aautonomiaea autoridadeda empresa, como centro deinteresses econômicos.

O boicotedenegros a umalinha deônibus da cidade de Montgomery, em 1955, élembrado como um dos primeiros sinais da pressão política, incentivada pela influência dos consumidores, cujas conseqüências econômicas acarretaram mudanças no comportamento das empresas. ${ }^{3}$ Pique tes eboicotes emlanchonetes deaproximadamente 140 cidades são partes dos eventos políticos que resultaram no A to dos Direitos Civis em 1964. A eleseagregam outros, sit-ins emanifestações, que sesomaram às exigências feitas às empresas para quecontratassem empregadosnegros. Em 1964, a empresa Kodak, em Rochester (NY), foi pressionada pelas organizações religiosas brancas enegrasa promover uma maior incorporação da população negra no seu estabelecimento. A escol ha dessa empresa não foi por acaso. A Kodak havia coope rado publicamente com o Comitê do presidente Kennedy paraa elaboração do "Plano Oportunidades Iguais para o Progresso". Esseevento desloca para a arena nacional o debate sobre natureza da responsabilidade social das empresas. Seguindo esseexemplo, também a empresa Xerox concorda emsetornar parceira da Freedom Integration God Honor Today - FIGHT. Boicotesnas empresas PepsiCola, Gulf eSun Oil foram particularmenteefeti-

${ }^{3}$ O slogan "Todo negro na cidade não deveria tomar os ônibus por um dia, em protesto" custou à empresa rodoviária da cidade de Montgomery mais de $\$ 7.000$ por dia em perdas de rendimento (Vogel, 1978b). vos, tanto que, em mais detrinta empresas, foram criados mais decinco mil empregos para a população negra. Esses são al guns dos exemplos que introduzema noção dequeas empresas têm a responsabilidade de el evar a qualidade de vida nas cidades edeintegrar a popul ação negra ao merca do detrabal ho.

As exigências do movimento contraa guerra do Vietnã, em relação às empresas, aconteceram num contexto consideravelmentediferente. Osradicais faziam uma crítica explícita às empresase ao sistema das corporações, publicando relatórios sobresuas políticas numa série deáreas, incl uindo proteção ambiental , investimento na África do Sul e disputas trabal histas. Nos anos 1960, uma das principais intervenções no comportamento das grandes empresas americanas foi referenteàquestão da produção industrial dearmamentos. Entre 1966 e 1969, os argumentos - que tiveram como alvo muitas corporações como a AT\&T, ITT, Bank of América, UNITED Aircraft, Honeywell, General Eletric eDow Chemical - apoiavam-seemelementos dediferentenatureza. O primeiroépolítico: as corporações eram vistas como a partemaisimportantee poderosa da economia política americana. Com efeito, cada uma das doze corporações que foram aval iadas tem em comum o envolvimento financeiro no esforço da guerra eno complexoindustrial militar. O segundo diz respeito aos desafios colocados pelos movimentos anti-guerra às empresas, quetêm uma dimensão moral particularmenteforte. A concepção protestantedaresponsabilidade individual está implícita. Num certo sentido, de acordo com D. Vogel, pedia-sequeas corporações tivessem "uma al ma" enão permitissem que os produtos do seu capital etrabal ho fossem utilizados para fins imorais. O movimento estudantil universitário americano também éincluídonessemovimento, poisreal izou mais de 183 manifestações contra osnegócios damultinacional do setor químico, a Dow Chemical (que produzia napalm) entre 1968 e $1969 .{ }^{4}$

O controlesobreas corporações foi realiza-

\footnotetext{
${ }^{4}$ Ao se tornar o símbolo do protesto estudantil, a Dow Chemical foi vista como corporação cujas ações podiam ser aval iadas pela responsabilidade moral (Vogel, 1978).
} 
dotambém pelalgrejaProtestante, queexerceu um importantepapel em monitorar as empresas americanas atuantes naÁfrica do Sul, enquanto a Ordem Católica exerceu al guma influência para as empresas que atuavam na América Latina. ${ }^{5} \mathrm{~A}$ origem desse ativismo social é vinculada à história antiga do Consel ho Nacional de Igrejas (NCC, sigla em inglês), um quarto de século antes de se tornar uma questão política. O sociólogo americano D. Vogel lembra que, desde 1947, tanto a Vida Econômica quanto a Vida Eclesiástica preocuparam-seem promover uma análise ética das questões econômicas. Em seguida, em 1963, o NCC tornou-se a primeira organização a sugerir publicamente que as relações de igual dade nas corporaçõesinfluenciama conduta social das empresas. Em 1966, a junta geral dessa instituição expandiu essaimplicação. Podemos sal ientar dois exemplos: o caso da Polaroid eo da IBM. ${ }^{6}$ Em 1963, a resolução das Nações Unidas decidiu por um embargo armamentista à África do Sul. ${ }^{7}$ Em 1969, um pequeno número de empregados negros da empresa se uniu a um grupo militantedenominado Movimento dos Trabal hadores Revolucionários da Polaroid (PRWM, sigla em inglês) edistribuíram panfletos acusando: "Polaroid aprisiona negrosem 60 segundos". Osmanifestantes argumentavam que os produtos da Polaroid estavam sendo usados no sistema de cartão de identificação na África doSul econvocaram um boicoteinternacional. Em 1970, a empresa Polaroid publicou uma declaração quenegavaa utilização do equipamento da empresa no programa deidentificação. Ademais, a própria empresa afirmou ter instruídoseus

${ }^{5}$ Para D. Vogel, o interesse das I grejas nesse tipo de questão está ligado à ativação de poderes também econômicos por elas. Com efeito, as Igrejas são instituicõ̃es econômicas significativas cujos recursos, em 1979, estavam estimados em mais de 160 bilhões de dólares nos EUA. Ademais, são instituições cujos princípios legitimadores podem ser e, com mai or probabilidade, são importantes instituições com fundos disponíveis.

${ }^{6}$ Vogel refere-se a outras ações dos movimentos eclesiásticos: na Namíbia em 1966-67; em Angola em 1969; e o boicote árabe nos EUA, em 1975-76 (Vogel, 1978).

${ }^{7}$ Lembramos que, em 1970, as Nações Unidas, com a abstenção dos EUA, expandiram o embargo, exigindo que diversos Estados proibissem "o investimento ou a assistência técnica à manufatura de armas e munições, aeronaves... e outros veículos militares" (Vogel, 1978 p.249). distribuidores locais a interromper a venda de qual quer produto para o governo daÁfrica do Sul, incluindo filmesa serem usados emtal programa. O diretor de relações públicas da empresa assim declarou: "Temos responsabilidade pelo uso final do nosso produto... Em respostaao grandePRWM, articulamos uma política muito estrita derecusa a fazer negócios diretamentecom o governo sul-africano... Nós, na condição de corporação, não venderemos nossos produtos em casos em que seu uso constituauma redução potencial daliberdade humana" (Vogel, 1978, p.173).

O movimento eclesiástico, em 1974, monitorou o comportamento da empresa americanaIBM, a partir da legal idadee da moral idadena venda decomputadores paraaÁfrica do Sul, afirmando que os computadores aumentam a eficiência do sistema decaderneta bancária sul-africanae podem ser usados para o desenvolvimento da capacidade nuclear da África do Sul. Além disso, foi dito quea IBM desejava vender seus produtos para fortal ecer a capacidade de repressão do governo daquele país. Longedeser umato comercial simples eneutro, a distribuição eo uso de computadores foram vistosa partir de suas conseqüências políticas.

Paraconcluir, entreasações demonitoramento das corporações americanas, devemos incluir os grupos organizados de acionistas que buscam politizar o gerenciamento das empresas (Vogel, 1983). Semprecom referência à África do Sul, as reuniões anuais deacionistas são espaços quetornam públicos os desacordos frenteàs políticas das grandes empresas americanas. Entre 1970 e1977, há resoluções deacionistas que, agindo junto aos movimentos eclesiásticos, se mobilizaram para sugerir maior transparência das empresas em suas políticas internas de empregos. O caso mais conhecido éaquele protagonizado por um pequeno grupo de advogados que, em 1970, organizou o Projeto acerca da Responsabilidade Corporativa (PCR, sigla em inglês). Esse grupo, em virtude de sua propriedadecoletiva dedozeações, anunciou, em entrevista col etivaàimprensa, queestava prestes a submeter noveresol uções aos 1.300 .000 aci- 
onistas da empresa automotiva GM. Os objetivos sugeridos pelo grupo deacionistas são: encorajar o máximo dedebates possíveis sobrea re ação entre responsabilidade corporativa e autoridade gerencial; permitir queos investidores expressem seu desprazer com o desempenho social da GM, compartilhando votos sobre várias propostas contra os gerentes; expandir o consel ho de diretores para vinte e seis, a fim de abrir espaço para três diretores adicionais ecriar umcomitêpara responsabilidadecorporativa.

Em 1972, por exemplo, a Mobil foi aúnica empresa a fornecer os dados sobre suas práticas de emprego. Em seguida, Ford, GM, Gulf, ITT, Texaco, 3M, Xerox, Col gate-Palmolive, Gillette, entreoutras, fizeram o mesmo. Polaroid eITT estabel eceram comitês especiais de inspeção para examinaremas práticas daempresanessatemática, seguindo os pedidos dos movimentos eclesiásticos dalgreja.

Essas diversas formas de pressão, exercidas sobreas empresas nos EUA, nos anos 1960-1977, evidenciamo ajustedas práticas das empresas no quediz respeito à configuração eà composição de seus empregados; à defesa dos direitos humanos no seu interior e (ou) nas sociedades onde comercializam seus produtos; à escol ha dos mercados consumidores; eà escol ha privilegiada de clientes internacionais. Assim, o círculo deatores e instituições que sugerem a Responsabilidade Social Empresarial - RSE - éum cenário quenão éprefixado. Ao contrário, eleseexpandeesearticulacomaagenda nacional, deacordo com a capa cidade demobilização de grupos esetores organizados, bem como em função desua vitalidadeem proporcionar a formação de porta-vozes queinterpretemas exigências di spersas na soci edade.

\section{O MEIO EMPRESARIAL BRASILEIRO E A RESPONSABILIDADE SOCIAL}

Seo interessemundial empresarial pelaresponsabilidadesocial pareceapresentar-secommais ênfasena década de 1990, no Brasil, a emergência desse lema tem início nos anos 1960, quando algumas associações empresariais introduzem valores e princípios éticos como componentes da gestão daempresa. Tal preocupaçãoéumatímidacontribuição do ambienteempresarial próximo ao pensamento religi oso progressista, em adesão ao processo de redemocratização do Estado dedireito no Brasil. Mas seconstitui como parteda posição que critica a atitude tradicional do empresariado, até então profundamentemarcada por comportamentos autárquicos eautoritários. São pionei ras duas entidades. Inicialmentea Associação dos Dirigentes Cristãos deEmpresas do Brasil (ADCE-Brasil), fundada em São Paulo, em 1961. As atividades da ADCE no Brasil inspiraram um debatesobreo pape social das empresas e, em especial, a publicação pela filial paulista, em 1965, da Carta de Princípios do Dirigente Cristão de Empresas. Em 1974, a associação publicou outro importante documento, O Decálogo do Empresário, a primei ra proposta clara de ligar a gestão empresarial com a responsabilidade social. Para a ADCE-RJ, há indicações de que "imperfeições sociais" coexistem com o progresso eatépodem ser causadas por ele. A principal missão da entidadeéestabel ecer ligaçõesentreo espaço das organizações empresariais eo contexto social, de modo que as ações sociais sejam um instrumento útil para a construção de uma nova cultura. ${ }^{8}$ Sucessivamente, em 1986, a Fundação Instituto deDesenvol vimento Empresarial e Social (Fides), em col aboração coma ADCE, propôs "humanizar a empresae promover sua relação coma sociedade". A Fides desenvolveinstrumentos educacionais e intelectuais específicos, bem como estabelece relações com autoridades ecumênicas, tal como aConferência Nacional dos Bispos do Brasil, criando um canal deinterlocução comos sindicatos dos trabal hadores.

\footnotetext{
${ }^{8} \mathrm{~A}$ rede criada pela $\mathrm{ADCE}$ desenvolveu novos instrumentos e estimulou a tradição católica da caridade. Seu principal objetivo, inspirado na encíclica do Papa Leão XIII, Rerum Novarum (1891), é aprofundar a reflexão sobre as implicações da visão cristã das práticas de concorrência econômica. Atualmente, a rede está presente na Europa, América Latina, África e Ásia, onde congrega associações nacionais.
} 
Outras três associações, num âmbito mais pragmático, apóiam a postura proativa do empresariado, quando se inaugura a conjuntura da redemocratização nos anos de 1980. A Câmara Americana deComércio deSão Paulo (AMCHAM - São Paulo), a partir de 1982, introduz o conceito de "cidadania corporativa", quando implementa a difusão de ações sociais empresariais. A associação instituiu o Prêmio Eco (empresa-comunidade), com o objetivo de incentivar ações sociaisnasáreas decultura, educação, meio ambiente, participação comunitária e saúde. O grupo Pensamento Nacional das Bases Empresariais - PNBE - sefez porta-voz darecomendação deestabel ecer um "pacto social" negociado. Em 1987, o PNBE, propondo dar prioridadeaos interesses nacionais, propagaos conceitos dedemocraciaecidadaniano meio empresarial, mobilizando-se em três âmbitos: a defesa deum pacto social nacional, o desenvolvimento nacional eo controleda inflação. ${ }^{9}$ Por fim, a rededeGrupo deInstitutos, Fundaçõese Empresas (GIFE) inaugura no Brasil , em 1985, umanova visão do interesse das empresas privadas no fomento a projetos sociais. O GIFE real iza sua primeira reunião em 1988, com um debate sobre filantropia, patrocinado por representantes das filiais brasileiras daAlcoa eda Kellogg Foundation, em col aboração coma Câmara Americana deComércio deSão Paulo. A proposta, sucessivamente espal hada por toda aAmérica Latina, éa dedefender a responsabilidadee a reciprocidade das empresas perantea sociedade, bem como a adoção de elevados padrões éticos deconduta comercial. 0 grupo propõe-sea col aborar com oEstado, em programas destinados a reduzir a desigual dadesocial, participar dedebates legislativosecontribuir como programanacional daComunidadeSolidária.

Nos anos 1990, a década em queas empre sas buscavam reestruturar-se para aumentar sua competitividadeno mercado internacional, al guns diretores - eespecialistas em gestão deempresas-

${ }^{9}$ Em 1992, a entidade teve um papel de liderança no processo de impeachment do Presidente Fernando Collor de Mello, e deu início a uma campanha pela cidadania e pela mel horia da qual idade de vida do povo brasileiro. associaram as iniciativas de responsabilidadesocial da empresa com propostas para racionalizar (reduzir) custos, aumentar as vantagens competitivas e administrar os riscos e a reputação de suas empresas. As repercussões internacionais de alguns indicadores sociais (incidentes detrabalho, trabalho infantil, trabal ho forçado, entre outros), ao proporcionarem uma imagem desfavorável, levaramal gumas empresas brasileiras a priorizar seu envolvimento emal gumas áreas específicas, entre as quais a pobreza, a violência, a educação ea proteção ao meio ambiente. A responsabilidadesocial da empresa tornou-se, assim, parte de uma estratégia mais ampla delegitimidade, uma maneira de limpar a imagem maculada dos empresários edas empresas, considerados por muitos como responsáveis pel a concentração da riqueza epel o caráter cada vez mai s especulativo dos investimentos financeiros. Em outras palavras, muitas empresase seus dirigentes brasileirosutilizaram-sedolemada responsabilidadesocial da empresa para restabelecer a confiança dos trabal hadores - aqueles quetinham permanecido empregados - após as significativasfusões, reestruturações emodernizações internas paraaumentar sua competitividadee, sobre tudo, consolidar afidelidadedos consumidoresea aceitação da col etividade. Numa época demerca dos de trabal ho flexíveis e de desregulamentação dos custos da mão-de-obra, a responsabilidade social permite às empresas amenizar os efeitos desses processos.

A ampliação da agenda de RSE, durantea década de 1990, se dá pelo circuito de doações empresariais, com recursos usados para real izar programas sociais voltados para atender à popula ção em situação de pobreza. Em outras pal avras, asempresaseentidadesempresariais dirigiramsuas ações sociais para fora de seus muros. Em contraste, são raros os investimentos para aumentar a qualificação dos trabal hadores, e, assim, al cançarem o grau de educação necessário para acompanhar a modernização das técnicas de produção usadas nos locais detrabal ho, sobretudo nos setores metalúrgico, químico, têxtil e de construção civil. 
Essa segunda onda da difusão da responsa bilidade social da empresa no Brasil surge num contexto de desregulamentaçãoe edeterioração das normas edireitos do trabal ho. Enquanto háaênfase em discursos e práticas de tal responsabilidade, várias empresas, diferentes associações efederações empresariais fazem pressão sobreo Estado para queas normas detrabal ho eos direitos trabaIhistas sejam excluídos da legi sl ação nacional e transferidos para a órbita da negociação coletiva direta. Essa proposta das grandes empresas, dese abandonar o paradigmauniversal ista da legislação trabal hista éuma forma de reduzir, com amparo legal, a formação de empregos protegidos por regras egarantias previdenciárias, enxugar o volume detrabal hadores contratadose, graças à substituição eà rotatividadeda mão-de-obra, atédiminuir os salários. Vista nesse contexto, a responsabilidadesocial da empresa aparececomo uma "abordagem paliativa", a fim demitigar, utilizandomedidas filantrópicas, os danos maiores que acarre tam para a sociedade.

\section{AS INICIATIVAS INSTITUCIONAIS RECENTES}

As cinco redes citadas (ADCE, Amcham, FIDES, PNBE eGIFE) estão na raiz da concepção atual do papel positivo das empresas privadas na sociedade. Delas saíram muitas análises emotivações paraa articulação entreobjetivos econômicose objetivos sociai s, quedizem respeito, sobretudo, a valores políticos e espirituais, etambém às interpretações relacionadascomas demandascívicas pela transparência das ações estatais eempresariais.

No fim dos anos 1990, em uma nova conjuntura política, as iniciativas empresariais deresponsabilidade social aumentaram o leque deentendimento desse lema. Os programas sociais se orientam pel as recentes mudanças institucionais queabrem novos compromissos, viabilizados pela descentralização das políticas de educação, transportes, saúdee meio ambiente, a criação do Estatuto da Criança e do Adolescente, do Código de Defesa do Consumidor ealei federal deincentivo fiscal aos investimentos de apoio à cultura. Mais ainda: conectam-se, em 1994, coma política nacional do governo Fernando Henrique Cardoso no interior do programa "Mãosà Obra Brasil". Nesse momento, é ampliada a parceria entre Estado e sociedade, estimulando-seo desenvolvimento do chamado Terceiro Setor. Inspiradas no modelo norte-americano, muitas empresas privadas (nacionaisemultinacionais), no Brasil, abraçaram essa política, aumentando o número de fundaçõesempresariais, financiando organizações sem finslucrativos einstituindo departamentos deresponsa bilidadesocial nas empresas. Um pequeno número deempresas já havia incorporado essas teses, e al gumas firmas eassociações empresariai s procuraram adaptálas aos seus objetivos, el aborandoe divulgando iniciativas sociais.

Duranteas el eições presidenciais de 1994, al guns empresários quefaziam partedo Fórum da Média e Pequena Empresa (Fopeme) fundam a Associação Brasileira de Empresários pela Cidadania (Cives). Essa entidadepolíticatem por finalidade, segundo o seu programa, o desenvolvimento da cidadania, o aperfei çoamento da democracia, a defesa dajustiça social eda ética. Nas décadas de 1980 e 1990, o grupo Cives participou de várias iniciativas políticas tais como: o Movimento pela Ética na Política e o Pensamento Nacional das Bases Empresariais - PNBE. Em 1994, define como seu principal objetivo a reforma estrutural do Estado, inclusi ve a reforma fiscal, a adoção deum sistema progressivo deimposto derendaea defesa dauniversalização dos direitos trabal histas.

Em 1998, outro grupo adereao discurso da responsabilidade social empresarial: o Instituto Ethos, fundado em São Paulo como organização privada, patrocinadapor mais de 400 empresas, que participam como membros associados. O Instituto desenvolve parcerias internacionais com grupos afins, como o Business for Social Responsability (BSR), olnstituto Kellogg, o International Business Leaders Forum eo United Nations Global Compact. A razão básica para essetipo derelacionamento re side na visão do Instituto sobre o papel social das empresas. Valendo-se deseu poder econômico, as 
empresas deveriam ser capazes de promover amudança cultural, istoé, delevar novos val ores àscomunidades. Em consonância coma missão dolnstituto, aresponsabilidadesocial deveria aumentar a capacidadedeas empresas fazerem investimentos quefortal eçam, ao mesmo tempo, as redes sociaise econômicas, além dedisseminar esseconceito para as redes de seus stakeholders. Por isso, o Instituto Ethos recomenda que seus membros promovam a imagem das empresas como agentes civilizadores das condições comunitárias queas cercam.

Para exemplificar a visão empresarial que interpreta a responsabilidade social no Brasil no período de maior ressonância de sua divulgação nacional, citamos al guns depoimentos divul gados no jornal cariocaO Globo, que, em 2003, inaugura o suplemento mensal: Razão Social. Essa iniciativa fomenta a criação de uma cultura positiva do comportamento e das práticas sociais das empresas, demonstrando queelas têm instrumentos para adotar uma postura proativa junto à sociedade, colaborando com o bem-estar da população.

Entrevista a Antonio Ermírio de Morais Grupo Votorantim:

A responsabilidade social é fundamental para o país crescer de maneira ordeira e inteligente.... Nós compramos essa companhia Brasileira de alumínio em 1955 e tinha 75\% de funcionários analfabetos. Hojenão tem nenhum. Pelo contrário: $80 \%$ têm ensino completo. E muita gente está seformando pela companhia. Naquel a época não sefal ava de responsabili dadesocial como se fala hoje. Isso é um sentimento humano, de ajudar o próximo, tem que estar no DNA do empresário. (Razão Social, n.6, nov., 2003.)

Entrevista a Arthur Sendas- Presidentedo Grupo Sendas:

Eu acho queo empresário temo dever de col aborar, de partici par, fazer a parte dele. Mas não dá para assumir totalmente. Até porque, com a gl obal ização, as maiores empresas no mundo estão atuando aqui livremente, há muita competitividade e elas pagam juros bem diferentes. Enquanto lá fora são juros de 3,4\%, aqui é 25 vezes mais. Portanto o empresário faz o que pode, mas tem limites. E o governo também precisa atuar. Afinal nós contribuímos para ele. (Razão Social, n.7, dez., 2003)
Entrevista a Marcos Magal hães- Presidente da Philips

Nosso grandeguardachuvaéa educação, paraajudar o público externo, mas com chances de beneficiar nossos funcionários também. Láatrás, quando começamos a estruturar nossas ações, foi pela filantropia. Atéque decidimos focar na educação, pelo motivo óbvio de contribuir mais como país. O Brasil temum espaço grandedemais entreo poder econômico (150 do mundo) eo índicededesenvolvimento humano (72). Essa distância tem que diminuir. (Razão Social, n.15, ago., 2004)

Entrevista a João Brandão - Diretor da Rio Polímeros:

...A responsabilidade social faz parte do processo de sobrevivência das empresas. A empresa que exerce a responsabilidade social é mais facilmente aceita pela comunidade. Dessa forma, é mais fácil se perpetuar. É um comportamento que está se disseminando largamente." (Razão Social, n.24, maio, 2005)

Desseconjunto tão diverso emergeumaconvivênciadediferentes entendimentos, defilosofias quenemsemprecoincidem entresi..$^{10} \mathrm{~A}$ ênfasedos programasimplementados permanece demarcada por metas de responsabilidade voltadas a oferecer serviços gratuitos (alimentação, assistência, etc.) às pessoas excluídas devínculos formais deemprego. Tais iniciativas eprogramas não incluem proposta al guma para reverter as políticas sel etivas de oferta de empregos, com o fim de reduzir a persistente taxa deemprego informal.

\section{RENOVANDO A FUNÇÃO SOCIAL DAS EM- PRESAS NA UNIÃO EUROPÉIA}

A introdução do tema da responsabilidade social da empresa nas diretrizes da União Européia-UE - teminício em 1995, quando umgrupo devinteempresas assinou, junto à presidência da

${ }^{10}$ Não queremos diminuir a colaboração da sociedade civil organizada na construção do lema da RS. Ela tem início muito timidamente em 1999, quando o IBASE lança a campanha nacional do Bal anço Social e quando o Partido dos Trabalhadores elabora uma proposta de lei para a obrigatoriedade desse documento junto às empresas. $\mathrm{O}$ detalhamento dessa iniciativa, assim como a das Prefeituras, éobjeto deoutro artigo deCappellin; Giuliani (2004). 
eu, o documento European Business Declaration against Social Exclusion. Nessedocumento estão contidas as mais importantes diretrizes que motivam, do ponto de vista empresarial , a adesão das empresas àluta contra a exclusão social. Paralutar e prevenir a exclusão social, o apelo da UE à empresaéfazer com queelas renovemsua finalidade: ser fonte deempregos. É graças a esselaço que as empresas encontram formas derestabel ecer os vínculos de reciprocidade junto à sociedade. Mais ainda: afirma-seque "o setor privado eas empre sas públicas, ao prevenirem e combaterem a exclusão, podem elevar sua produtividade e suas metas de lucratividade"' (União Européia, 1995). Essa meta é assim assumida como um compromisso queexigeumainteração estreitaedinâmica, naEuropa, entreas políticas econômicas eas políticas sociais, visto quese devefazer frente a mais de 17 mil hões de pessoas desempregadas, 53 miI hões vivendo abai xo dal inha da pobreza, ede $3 a$ 5 milhões semadequadas condições dehabitação. A convocação deempresas européias na adesão à responsabilidade social como compromisso, em 1999, inclui os territórios nacionais, ${ }^{11}$ os países do Eastern Europe eos paísesem desenvol vimento.

Em seguida, em 2000, na ocasião do Encontro de Lisboa, é redigido um apelo a favor da responsabilidade social. Nesse fórum, há uma ampliação das enti dades envolvidas, já queo primeiro ministro da UE, a Comissão Européia e a primeira direção daCSR Europe (ResponsabilidadeSocial Corporativa), secomprometem a elaborar um atual izado programa demetas para2010. 0 desafio é saber conjugar o tripé: excelência e sustentabilidadedo desenvolvimento econômico; mais emel hores empregos; eo aumento da coesão social. O documento, PARTNERSHIP ALCHEMY. New Social Partnerships in Europe (União Européia, 2000) éum dos primeiros textos queresume os desafios deal guns países da Europa, ${ }^{12}$ editado

${ }^{11}$ A té 1999 , mais de 50 empresas aderem ao lema da Responsabilidade Social, conectando 15 países europeus.

${ }^{12}$ As informações detal hadas das iniciativas promovidas entre as empresas e os governos nacionais nas áreas de desenvolvimento fazem referências aos países: Grécia, Áustria, Bél gica, Alemanha, Espanha, Portugal, Finlândia elrlanda. pelo The Copenhagen Centre - TCC - em 2000. Nesse documento, são ressal tados os desafios no momento em que a nova real idade da economia gl obal, as transformações tecnológicas eas mudanças demográficas semanifestam em consonância coma transição política dos últimos anos do milênio. Nessa compl exa combinação, estão sendo criadas novas e inesperadas oportunidades para alguns cidadãos europeus, lado a lado com o aumento da insegurança e da desigual dadepara outros. Em cada real idadenacional, constata-seque uma abertura cosmopolita de possi bilidades, o uso deal ta tecnologia eo acesso a serviços sociais são acompanhados pela existência deáreas ondeháo aumento do desemprego, a persistência de habilidades de trabal ho não apropriadas aos desafios tecnológicos, baixos rendimentos, precárias condições residenciais, insucessos familiares, criminalidade, conflitos étnicos e degradação ambiental. A profundidadedessa distância social entre quem é beneficiário e quem está excluído ameaça o sucesso da integração européia, assim como seu al mejado desenvol vimento. No conjunto dos desafi os que os países devem enfrentar, são também incluídos os processos de privatização, daliberal ização e da abertura das comunicações, o que, nos últimos quinze anos, tem colocado em evidência o setor privado. Para os autores deste Relatório, essas questões sugeremo envolvimento tanto dos empresários e desuas lideranças como das organizações sindicais e das instituições locais. É justamente no interior das instâncias que envolvem o Estado, o mercado ea sociedadecivil, queépossível o equilíbrio dos poderesea assunção das responsabilidadesque, anteriormente, constituíam tarefas exclusi vas dos governos nacionais. Estes processos, continua o relatório, têmevidenciado o aumento da atenção pública em direção às atividades do businesse, conseqüentemente, solicitamo estreitamento das relações edos compromissos das empresas no interior da sociedade. O de senvolvimentoé, assim, escol hido como centro das práticas do business em toda sociedade européia. Final mente, como parteda exigência decoesão, no Relatório faz-seexplícitamenção ao papel dos par- 
ceiros sociais, que "deveriam inovar suastradicionais interações" (TCC, 2000, p.20). Os parcei ros, isto é, os representantes dos empregadores e dos trabal hadores, são mencionados como atores que fomentam o diál ogo social, envolvendo numerosos setores industriais emilhões detrabal hadores na Europa, nos diferentes países e em diferentes territórios locais. O tradicional envolvimento desses atores éevidentepel o legado dos procedimentos dediálogo, deconsultas, denegociações coletivas, de representações diretas nas entidades e, emalguns casos, como na Bél gica ena França, re presentações nos fundos de seguro social. Tais práticas deveriam permanecer ativas, justamente porque podem estimular uma maior competitividadeinternacional, aliada à coesão social. Além deser mencionado como prática tradicional européia, o diálogo social éincentivado visando a aumentar sua eficácia e criatividade e objetivando instaurar parcerias entreempregados eempregadores na Europa, em âmbito nacional e local (TCC, 2000, p.20). Nesses termos, fica claro quehá uma preocupação em chamar a atenção da empresa, a fim dequeela aprimore a capacidade de somar suas funções, renovando seu envol vimento na recuperação dos el os sociais de reciprocidade na sociedade contemporânea. $\mathrm{O}$ emprego, nessecontexto, éapontado como aquestão central. As empresas, como agentes econômicos, são solicitadas a transformarem-se em espaços em que essa meta é adotada como parte da responsabilidade social. Entre os exemplos de ações a serem promovidas, são citadas: estimular eincentivar o aumento da qualificação dos trabaIhadores; oferecer fontes detrabal ho referentes ao control edeacidentes, criar umambienteseguro e capaz de proteger física e psicol ogicamentequem neletrabal ha; proporcionar aigual dadedeoportunidades entre os sexos no acesso à ascensão e à carreira. Essas metas deresponsabilidadenão isolam a empresa do contexto social, mas justamente, por solicitarem um aprofundamento de seu papel social, recuperam os víncul os, as conexões institucionais, istoé, sol icitamo envol vimento em respeito às regras e às normas legais que foram pactuadas, juntamenteàs instâncias reguladoras: o Ministério do Trabalho, as Prefeituras, as entidades de representação de interesses, dos trabaIhadores, dos empregadores, dos consumidores.

Esse conjunto de objetivos é solicitado a todos os agentes econômicos, ou seja, a todo e qual quer tipo de empresa: as pequenas e médias empresas eas multinacionais, em todos os setores deatividades.

As reuniões promovidas no âmbito da Comissão Européia, desde 1999, deságuam na edição final da primeira diretriz européia, o Livro Verde, cujo título éPromover um quadro europeu para a responsabilidade social das empresas, editado em 2001. A proposta deresponsabilidadesocial, nesseLivro, coloca as empresas em contato direto com um ulterior desafio da sociedade contemporânea: aprimorar rel ações sol idárias. Isto é, competeaos agentes econômi cos favorecer os mai sal tos níveis decoesão social entreos setores dasociedade. Esse objetivo seexpressa na definição de responsabilidade social: "integração voluntária de preocupações sociais eambientais por parte das empresas nas suas operações e na sua interação com as outras partes interessadas" (União Européia, 2001).

Encontraremosmaiores conexões dessa diretriz searticularmos o Livro Verde com os novos princípios eval ores da Carta dos Direitos Fundamentais ${ }^{13}(2000)$. São outros exemplos dessa articulação os parâmetros já em voga do Global Compact, os princípios diretivos da Organização paraaCooperação eDesenvol vimento Econômico - OCDE - eas próprias convenções resumidas na assim chamada agenda social da Organização Internacional do Trabalho- OIT. A metaéunificare harmonizar, no diversificado território europeu, alguns princípios de funcionamento a serem adotados. Caberia às empresas:

- "Adotar um comportamento social menteresponsável, indo al ém das prescrições legais, se envolvendo em práticas vol untárias como partede seus interesses de mai s longo al cance";

${ }^{13}$ A Carta dos Direitos Fundamentais da União Européia foi enunciada em Nice, em 7 de dezembro de 2000. Essa Carta é o resultado de um procedimento original, sem precedentes na história da Unnião Européia. 
- Considerar que "a RS é intrinsecamente conectada ao conceito de desenvol vimento sustentável: as empresas deveriam integrar os efeitos econômicos, sociais e ambientais, na suas práticas degestão";

- Perceber que “a RS não éuma opção a ser acrescidaàs atividades centrais daempresas, mas está vinculada a escolhas e desafios de sua gestão interna".

Dessas ênfases, fica claro que se está moldando critérios inovadores, assumidos como ferramentas degestão do assim chamado governo da empresa, ${ }^{14}$ de grande utilidade para se enfrentaremas transformaçõescontemporâneas. É aqui que a inserção no mercado não requer o abandono das regras enormas para concorrer internacional mente, mas refina as posturas a serem seguidas, para queas empresas possam semovimentar no amplo contexto internacional. Sea conjuntura mundial envolvedesafios, éimportantequesejam adotadas novas e apropriadas posturas empresariais. No texto do Livro Verde, são citados al guns exemplos:

- A globalização tem aberto para as empresas novas perspectivas, mas estas têmmodificado tambémasua estruturainterna, fazendo-amaiscomplexa. Sua movimentação nos espaços de mercado internacional exige maiores e mais aprofundados compromissos juntamente aos países em via de desenvolvimento.

- A força dos mecanismos de elaboração da imagem da empresa e da reputação funcionam para enfrentar o ambiente competitivo justamente quando os consumidores eas organizações não governamentais ficam mai s atentas às informações sobreas condições de produção dos bense sobre seus efeitos para o desenvolvimento. Neste sentido, estes mecanismos da imagem podem ajudar a recompensar as empresas emseuscomportamentos e em suas atitudes sociais e ambientais.

${ }^{14}$ Adotamos a definição do sociólogo L. Gallino (2005), quando faz referência ao governo da empresa, isto é, à estrutura do chamado governo da empresa, conhecida no âmbito teórico como "governança corporativa [que se funda] em uma articulação bastante complexa da distribuição do poder de decisão entre os acionistas, os dirigentes administrativos e os dirigentes técnicos."
- As conseqüências das modificações exigem que tambémas intervenções einvestimentos financeiros sejam mais transparentes, para melhor permitir a identificação dos fatores derisco, do sucesso, para enfim atender às demandas da opinião pública que requer o fornecimento de informações mais extensas daquelas clássicas do desempenho financeiro.

- O conhecimento e a inovação são hoje sempre mais cruciais para aprimorar a competição e, conseqüentemente, adquirirem mai oresinteresses se contratam pessoas competentes e bem qualificadas.

Final mente, nesse Livro Verde, são renovados os compromissos de adesão à responsabilidade social por parte das organizações. O primeiro compromisso daempresaéfomentar "parceriaspara o crescimento e para o emprego". Dessa forma, em umambientepúblico europeu, os empresários são apreciados não apenas pel os lucros obtidos, mas também por oferecerem uma contribuição importantena resolução dos problemas da sociedade ${ }^{15}$

Sucessivamente, todas as práticas sociais promovidas pelas empresas não devem ser consideradas como uma substituição das regulamentações eda legislação referentes aos direitos sociais ou normas ambientais. Ao contrário, nos países onde tais regulamentações não existem ainda, a orientação da ResponsabilidadeSocial dasEmpresas Européias é a de promover esforços para “a criação de um contexto queajudea regulamentar as fontes legislativas, com o fim de chegar a uma baseeqüitativa, fonte para sucessivos desenvolvimentos de práticas sociais responsáveis". ${ }^{16}$ Após

${ }^{15}$ A pós as reuniões de Lisboa, fala-se: “Mais que nunca, a Europa precisa de empresários ativos, atitudes positivas em relação ao espírito empresarial e confiança nas empresas. A Europa necessita de um clima público no qual os empresários sejam apreciados não apenas pelos lucros que têm, mas também por darem um apoio importante para a resolução de certos problemas da sociedade" (União Européia, 2006).

16 “A visão européia de prosperidade, solidariedade e segurança em longo prazo al arga-se também à esfera internacional. A Comi ssão reconhece as ligações entre a aceitação da responsabilidade social da empresa na Europa e no resto do mundo e considera que as empresas européias devem comportar-se de forma responsável onde quer que operem, de acordo com os val ores europeus e as normas internacionais" (2006, p.6). 
a divulgação do Livro Verde, multiplicam-seasiniciativas de debatee de articulação junto ao Parlamento Europeu. ${ }^{17}$ Emsíntese, emergem diferentes comentários recol hidos juntos às organizações que acolhem esselema (União Européia, 2002):

- A responsabilidade social é destacada pelas empresas como sendo de natureza vol untária e estas consi deram queo concei to não poderá ser aplicado de maneira uniforme, dada a diversidade das abordagens nacionais.

- Os sindicatos e as organizações da sociedade civil sal ientam queas iniciativas vol untárias não são suficientes para proteger os trabal hadores. Requerem, assim, às empresas que tornem conheci das as suas atividades no domínio social, através demecanismos eficazes.

- Os investidores sublinham a necessidade de mel horar a divul gação deinformações eatransparência quanto às práticas das empresas.

- As organizações de consumidores sal ientam a importância dedispor deinformações confiáveis sobre as condições de produção e venda dos bens.

- Asinstituições européias - como o Conselho, o ComitêEconômico eSocial Europeu, o Comitê das Regiões e o Parlamento Europeu - assina lama importância deuma abordagem européia sobre o assunto.

A Comissão Européia, ainda em 2006, estende seu compromisso, fazendo um apelo para que as empresas não se percebam "substituindo as ações dos poderes públicos" (União Européia, 2006). É nessa ocasião que são renovados e detaIhados os mais atuais objetivoseiniciativas deresponsabilidadesocial, tais como:

- Maior integração dos mercados de trabal ho e melhores níveis de inclusão social, na medida emqueas empresas procurem ativamenterecrutar mais pessoas de grupos desfavorecidos.

- Investimento no desenvolvimento das competências, na formação contínua e na empregabilidade, quesão necessários para manter a competiti vidade na economia do conheci-

${ }^{17}$ Essas etapas de consulta estão registradas no documento (2002). mento em nível gl obal e em face do envel hecimento da população ativa na Europa.

- Mel horias na saúde pública, em conseqüência deiniciativas vol untárias das empresas em domínios como a comercialização e a rotulagem dos al imentos e das substâncias químicas não tóxicas.

- Um melhor desempenho em matéria deinova ção, no que se refere às inovações dirigi das a problemas da sociedade, em conseqüência de uma interação mais intensiva com os agentes externos e da criação de ambientes de trabal ho mais propícios à inovação.

- Maior respeito pel os direitos humanos, pelaproteção do ambiente e pelas normas trabal histas básicas, nomeadamente nos países em vias de desenvolvimento.

- Reduzir a pobreza e evol uir no sentido de concretizar os objetivos de Desenvolvimento do Milênio. ${ }^{18}$

Finalmente, há uma particular atenção em sereconhecer o uso deferramentas queampliama transparência das práticas de responsabilidade social, a fim de que as práticas vol untárias sejam visíveis edefácil análise comparativa (União Européia, 2002). Nesse âmbito, são incluídos os códigos deconduta, ${ }^{19}$ as normas de gestão, ${ }^{20}$ as normas deperformanceeos relatórios devalidação, ${ }^{21}$ os rótul os eetiquetas, ${ }^{22}$ eos investimentos socialmenteresponsáveis. ${ }^{23}$

Em 2007, o processo de difusão da CSR consegueenvolver os vintee cinco países quefazem parte da União Européia (União Européia,

18 É também mencionada a preocupação de as empresas promoverem a incorporação da i gual dade de gênero. Ver Documento: União Européia, COM (2006), n.136.

${ }^{19}$ Códigos de conduta: direitos dos trabal hadores, direitos humanos, proteção do ambiente, etc.

20 Normas de gestão: integração dos aspectos sociais e ambientais nas atividades quotidianas das empresas.

${ }^{21}$ Aferição dos desempenhos, elaboração de relatórios e validação (redação, pelas empresas, de relatórios internos sobre as suas atividades no domínio da RSE).

22 Rótulos (direito dos consumidores à informação sobre os produtos, através da rotulagem).

${ }^{23}$ ISR (investimento socialmente responsável, especialmente para os fundos de pensões, ou seja, há que investir nas empresas que obtêm os melhores resultados em termos de RSE). 
2007). As diferentes modal idades deorganização, que modal idades estão ativas, que incentivos estão di sponíveis para as empresas equeferramentas detransparência evisi bilidadesão encaminhadas são alguns dos tópicos do Compendium on national public policies on CSR in the European Union, o mais recentedocumento do bal anço interno daUnião Européia sobrea ResponsabilidadeSocial (2007).

\section{CONCLUSÕES}

As perspectivas, as políticas e as redes institucionais não parecem ser uniformes quanto à proposta da Responsabilidade Social nos EUA, no Brasil enaUnião Européia. Se, por umlado, as dinâmi cas dagl obal ização ampliamesselema, por outro, os estímul os deadesão não homogenézam os entendimentos que acabamos de relatar. Com efeito, a difusão de iniciativas deresponsabilidadesocial épartedo ajuste do comportamento empresarial nos EUA. No Brasil, constitui-se como uma pluralidade deiniciativas encampadas diretamentepelas empresas atéo início dosanos 2000. E, naUE, éuma sol icitação central das instâncias multilaterais queestimulamas empresas aresponderem à atual crise do emprego. Esses exemplos constituem três portas de entrada para a problemática da responsabilidadesocial. É interessante não subestimar as dinâmicas que explicitam os caminhos pelos quais tais organizações trilham. Às vezes, acolhem as reivindicações que se formam no conjunto da sociedade (USA e UE), outras vezes, põem resistências a usar o emprego como metadaresponsabilidadesocial ese deslocam para várias iniciativas deassistência social, elaborando programas discricionários e unilaterais, como no caso do Brasil. Provavelmente é a partir desses encaminhamentostão variados quefaz sentido fa lar deinterações nacionais eregionais da ResponsabilidadeSocial dasEmpresas. O ol har sociológico podefixar as dinâmi cas eos processos através dos quais, na sociedade, as estruturas das organizações semol dam às exigências plurais, econômi- cas e extra-econômicas, de modo a col aborar com o desenvol vimento e para a coesão social.

No EUA, a responsabilidade se impôs à empresa com o fim de control ar política e socialmenteseus poderes e para deli mitar as frontei ras dasuafabul osa expansão econômica epolítica. Nos Estados Unidos, no decorrer dos anos 1930, no início do debate sobre a responsabilidade social, os grandes conglomerados multinacionais - as corporações - detinham sempremais poderes, interferindo até mesmo na esfera política nacional (Kaufman; Zacharias; Karson, 1995). Hoje, o estímulo à lealdade dos consumidores no mercado americano se estabelece a partir de relações contratuais queincluem critérios eprocedimentos de indenizações, obrigações e seguros, os quais fomentam o desenvolvimento da área disci plinar do "direito deresponsabilidade" (Engel, 1992).

No Brasil, as motivações - os moventes do lema da responsabilidade social da empresa ocorrem com o ajustee renovação dos sentidose dos conteúdos programáticos em períodos distintos. No momento inaugural, entreos anos 1960 a 1980, esseéum lema quesedifunde, em âmbitos empresariais associativos bastante restritos, mas ativos, quebuscam, inicialmente, conquistar alegitimidade na sociedade - que se preparava para recuperar as dinâmicas democráticas-, pelaintrodução deval oreséticos nas orientações empresariais. No segundo momento, entre 1990 e2002, são as próprias empresas como agentes eatores sociais que encampam a proposição. A diretriz mais em voga é a de realizar práticas e programas de filantropia assistencial. Nessa conjuntura, a autonomia da empresa privada, com ampla margem discricionária, aproveita a reforma do Estado de 1994, desprestigia a rede de reciprocidade social entre emprego e empresas, e se direciona para o apoio a iniciativas do terceiro setor, o qual desenvolve programas de assistência social. Isso épossível porque, após os anos 1994, inaugura-se, de acordo com as diretrizes constitucionais, a divisão das competências do Estado, no que tange à seguridade social. A prerrogativa de assistência social pública para a população situada à margem 
da integração ao emprego é ampliada até pelo envolvimento do tercei ro setor. As empresas denominam, como práticas de responsabilidadesocial, vários programas deassistênciaa essas populações, os quais vêm sendo desenhados com procedimentos de frágil diálogo público, sem introduzir mecanismos demonitoramento das relações de reciprocidade entre el as e seu entorno social (Peliano, 2001; Cappellin; Giuliani, 2004). O que as nossas pesquisas indicaméquea ampla divulgação da responsabilidade social coincide como desenvolvimento do movimento empresarial Custo Brasil, quesugerea diluição das garantias trabaIhistas, atéentão dirigidas pel o ideal dos direitos universais, a serem incluídas agora nas negociações contratuais col etivas. ${ }^{24}$

Trata-sedemetas privadas debem-estar social, na medida em queas áreas deintervenção, as final idades dos serviços e a definição dos públicos assistidos não são fruto detími das práticas de diál ogo ou negociação diretacomatoressociais (trabal hadores, população local, sindicatos, agências do poder estatal ). ${ }^{25}$ Frenteaos contextos internacionais (USA e UE), há certa resistência por parte das empresas, no Brasil, deseenvolverem diretamente na reversão da rel ação assimétrica entre a acumulação de riqueza e o bem-estar geral, assimetria queelas próprias fomentam. O queparece claro é que as empresas, mesmo real izando programas e serviços de assistência social, mantêm uma postura impermeável ao diálogo junto aos trabal hadores. Poderíamos até afirmar que é ai nda muito arrai gada e difusa a crença de quea empresa é uma estrutura autocrática, uma ilha

${ }^{24}$ A reforma constitucional foi enviada ao Ministério do Trabalho e apresentada para a Comissão de Assuntos Sociais do Senado Federal, desde 1997. Com isso, abrirse-ia um campo para se negociar uma série de encargos, especial mente aquel es dos capítul os referentes à remuneracão do tempo não trabal hado: férias, abono de férias, 130 salário, descansos remunerados, etc. Nessa negociação, nada garante que el es serão mais baixos ou mais al tos do que os atuais.

${ }^{25}$ Relembramos que, para O. De Leonardis, a trajetória do Welfare State oferece um legado ao estatuto público das políticas sociais. Para a autora, isso se expressa pel o fato de a formatação das políticas sociais fazer referência, sobretudo, a processos e planejamentos que al imentam o debate das questões a serem assumidas col etivamente, dos fins, dos significados, das escol has e dos interesses em jogo (Leonardis, 1999). sociotécnica, um sistema relativamenteautônomo degoverno.

No âmbito da União Européia, o uso do concei to deresponsabilidadecircula nos ambientes empresariais com um novo marco regulatório que reitera o fortal ecimento de propostas em circulação, já estabel eci das ao longo da historia das relações entre empresas, estado nacional esociedades locais. É justamente essa tentativa política quefortal ecea crítica sobrea autonomia dagestão das empresas, sugerida pel o mercado dos acionistas e investidores. É uma tentativa que busca reordenar a política debem-estar quefoi colocada em risco, fragilizada pel a prática deabandonar os pactos com as conquistas sindicais dos trabalhadores.

Os lemas demai or transparência administrativa efinanceira aliam-seàs sol icitações deque as empresas sai bamatender aexigênciasambientais ea causas sociais. No âmbi to da União Européia, o uso do concei to de responsabilidade começa a circular nosambientesempresariais como umapoio à regulação social , ${ }^{26}$ deforma a fortal ecer a propostajá em voga ao longo da historia das pol íticas do Estado Social (Castel, 1995). Essa preocupação, já presente no fim da década de 1960, é reiterada hoje, por ter deatual izar e reforçar, sob nova plataforma discursiva, as exigências já conquistadas, mas hojefragilizadas pel os ajustes à concorrência internacional epel os recentes comportamentos de externalização (escolha de outros contextos territoriais de produção ede mercado) de muitas empresas européias. Nessecontexto, parececlaro que a plataforma de maximização dos lucros, fomentada pelo maior poder dos investidores na gestão das empresas, fez alentar a agenda do desenvolvimento ebem-estar. É justamenteessa tentativa política dereaproximar os desafios do crescimento do bem-estar que evidencia o quanto é

\footnotetext{
${ }^{26}$ Referirmo-nos à regulação como: “o processo dinâmico de adaptar a produção e a demanda social, que resultam da conjugação de ajustes econômi cos associados a uma configuraçấo de formas institucionais. Num sistema dominado pela lógica do mercado, eas rel ačões capital istas, o sucesso da regulação pode ser medido pela atitude de guiar e canalizar o processo de acumulação, e conter os desequilíbrios." (Boyer, 1986, p.17).
} 
explícito o desejo, por parte das diretrizes da UE, dereordenar os processos quetêm reduzi do a coesão social: a expansão internacional das privatizações eali beral ização do mercado.

Recuperando as atitudes empresariais que visam a responder às necessi dades da sociedade, dever-se-ia afirmar quea responsabilidadesocial é um lema que se molda às interpretações soci opolíticas em vários espaços, nacionaisemultilaterais. O lemaderesponsabilidade social sugerido na União Européia acentua o fomento deemprego de qual idade, a ampliação decuidados contra práticas não discriminatórias derecrutamento, a sal vaguarda dos di reitos trabal histas, o aprimoramento da profissional ização, a modernização dos processos de produção, a parceria e o diál ogo social dedesenvolvimento local. No contexto brasileiro, essas metas parecem pouco enfatizadas. As práticas filantrópicas nem sempre conseguem superar o imediatismo das proposições assistenciais ecorrigir seu instável eirregular al cance social . ${ }^{27}$

É interessanteacompanhar edetal har, tendo como pano defundo o contexto internacional, a maneira como as instituições econômi cas brasileiras sedispõema alterar sua cultura autocrática, redefinindo-seentreos muitos atores sociais que, na sociedade contemporânea, inovamsuaresponsabilidadeno sei o da regulação social pública.

Recebido para publicação em setembro de 2007) (Aceito em novembro de 2007)

\section{REFERÊNCIAS}

ABEL, O. La responsabilité incertaine. Esprit, Paris, n.11, nov., 1994.

BERLE, Adolf; MEAN, G. The Modern Corporation and private propriety. New York: Harcort Brace \& World, 1968.

BOYER, R. La flexibilité du travail en Europe. Paris: Editions La Découverte, 1982.

${ }^{27}$ Lembramos a ênfase específica registrada no Livro Verde: "Através da sua participação no desenvolvimento local e em estratégias ativas para o mercado de trabal ho, mediante o seu envolvimento em parcerias locais de emprego e/ ou de inclusão social, as empresas podem mitigar o impacto social, a nível local, de acões de reestruturação de larga escala" (União Européia, 2001, p.11).
BRANDT, E., Nepalm. Public Relations Journal. New York, p. $12-15,1968$

CAPPELLIN, P ; GIULIANI, G.M. A economia política da responsabilidade social e ambiental nas empresas no Brasil. Programme on Technol ogy, Business and Society, Paper n.14. Geneva: UNRISD/UFRJ, 2006 (versão em português). Disponível em: www.unrisd.org. Acesso pelo nome dos autores.

et al. As organizações empresariais brasileiras e a responsabilidade social. In: ; KIRSHNER, A; GOMES, E. (Orgs) Empresa, empresáríos e globalização, Rio de Janeiro: Relume Dumará, 2002.

: DELGADO, D.: SOARES, V. As grandes empresas no Brasil: rel ações de gênero, trabal ho eigual dade de oportunidades. In: TERCER CONGRESO INTERNACIONAL DE LATINOAMERICANISTAS EN EUROPA. Amsterdam: 2002. (mimeo.)

CARROLL, A. B. Corporate social responsibility evolution of a definitional construct. Boston: Business \& Society, 1999 .

Three dimensional conceptual model of corporate social performance. Academy of Management Review, New York, n.4, 1979

Business and society, managing corporate social performance. Boston: Little Brown, 1981.

CASTEL, R. As metamorfoses da questão social. Uma crônica do salário. Petrópolis: Vozes, 1995

COMISSÃO DAS COMUNIDADES EUROPÉIAS. Livro Verde: promover um quadro europeu para a responsabilidade social das empresas. Bruxel as, 2001. Disponível em: http://europa.eu.int/comm/employment_social/soc-ial/ csr/csr index.htm

FREDEICK, W., The growing concern over business tesponsibility. Califónia: Management Review, 1960

GALLINO, L. L'impresa irresponsabile. Torino: Einaudi, 2005.

HIRSCHMAN, A. Saida, voz elealdade. S. Paulo: Perspectiva, 1970

LEONARDIS, de Ota. In un diverso Welafre. Sogni e incubi. Milano: Feltrinelli,1998.

KAUFMAN, A.; ZACHARIAS, L.; KARSON, M. Managers versus Owners. In: The struggle for corporate control in American democracy. Nova York: Oxford University Press, 1985

PELIANO, Anna Maria T. (Coord.) A iniciativa privada e o espírito público. Brasília: IPEA, 2001.

RICOEUR, P. Leconcept de responsabilité. Essai d'analyse sémantique. Esprit, Paris, n.11, nov., 1994.

SAINSAULIEU, R. et al. Vers une théorie sociologique de I'intreprise. Sociologie du Travail, Paris, n. 3, mai, 1986.

TOURAINE A. Critique de la modernité. Paris: Fayard, 1992.

UNIÃO EUROPÉIA. European business declaration against social exclusion, 1995. Disponível em: www.csreurope.org/aboutus/social exclusion_page393. aspx \#Principles of an overall strategy em:www.copenhageñceñtre.org/graphics/ CopenhagenCentre/Publications/Partnership_Alchemy.pdf

Carta dos Direitos Fundamentais, 2000. Disponível em: http://eur-lex.europa.eu/LexUriServ/site/pt/oj/ 2000/c 364/c 36420001218pt00010022.pdf

Livro Verde: promover um quadro europeu para a responsabilidade social das empresas, 2001. Disponível em: http://europa.eu/scadplus/leg/pt/cha/c00019.htm 
UNIÃO EUROPÉIA. CSR Europe.s response to the European Commission green paper for a European framework on CSR. Proposals for action, 2002. Disponível em: http://www.csreurope.org/uploadstore/cms/docs/ CSRE_Green_paper_response.pdf

. 2002 Disponível em: http://europa.eu/scadplus/leg/ pt/cha/c00019.htm

Communication de la Commission. La responsabilité sociale des entreprises: une contribution des entreprises au développement durable. COM (2002) n.347 final.

Implementação da parceria para o crescimento e o emprego COM (2006), n.136, p.4-5.
2006. Disponível em: http://eur-lex.europa.eu/ LexUriServ/site/pt/com/2006/com2006_0136pt01.pdf

2007. Disponível em: http://ec.europa.eu/ employment_social/emplweb/csr-matrix/csr_matrix_en.cfm VOGEL, D. Lobbing the corporation. New York: Basic Books, 1978.

Trends in shareholder activismo 1970-1982. California Management Review, n.3, maio, 1983. 


\section{AS EMPRESAS EM SOCIEDADES CONTEM- PORÂNEAS. A RESPONSABILIDADE SOCIAL NO NORTE E NO SUL}

\author{
Paola Cappellin \\ Raquel Giffoni
}

Neste artigo a difusão do lema da responsabilidade social é resgatada pela of social responsibility is rescued by the
analise de três percursos internacionais: analysis of three international trajectories: EUA, Brasil e União Européia. No pri- USA, Brazil and European Union. In the meiro caso, a vasta literatura sociológica first case, the vast sociological literature americana relata as preocupações e as American tells the concerns and the different pressões de diferentes atores sociais social actors' pressures on the American dos anos 1960. No Brasil, as primeiras first elaborations come from business
elaborações provêm de associações associations in the middle of the sixties and empresariais nos meados dos anos 60 e se are enlarged exactly when the society, at the dos anos 1990, demanda prosseguir na direction to integrate the commitment of direção a integrar o compromisso da the application of labor norms and rights. In aplicação das normas e direitos do trabalho. the European Union, the slogan of social Na União Européia, o lema da responsabi- responsibility is introduced in the end of the anos 1990 envolvendo o compromisso de around the high tax of structural fazer retroagir a alta taxa de desemprego unemployment. In the last section, the estrutural. Na última seção, a análise com- international comparative analysis suggests parativa internacional sugere recompor o a recomposition of the framework of several quadro dos diversos conteúdos da respon- contents of social responsibility starting from sabilidade social a partir da grande questão the great issue that is in debate in the
que está em debate nas sociedades: recom- societies: to recompose the commitment of por o compromisso de fortalecimento do invigoration of the job bond as source of vínculo de emprego como fonte de social citizenship. cidadania social. ampliam justo quando a sociedade, no fim end of the 1990's, demand to continue in a lidade social é introduzido nos finais dos 1990's involving the commitment of turning

LES ENTREPRISES DANS LE SOCIÉTÉS CONTEMPORAINES. LARESPONSABILITÉ SOCIALE DANSLE NORDETDANSLE SUD

Paola Cappellin

Raquel Giffoni

On retrouve, dans cet article, la diffusion du thème de la responsabilité sociale grâce à la reprise de l'analyse de trois évolutions internationales: les Etats-Unis, le Brésil et 'Union Européenne. Dans le premier cas, de nombreux écrits sociologiques américains décrivent les préoccupations et les pressions exercées par les différents acteurs sociaux sur es entreprises américaines au cours des années 1960. Au Brésil, les premières mises en oeuvre proviennent d'associa-tions d'entreprises vers e milieu des années 60 et s'amplifient à la fin des années 90, au moment où la société veut continuer dans la ligne de l'intégration pour que les normes et les droits du travail continuent à être appliqués. Au sein de l’Union Européenne, le thème de la responsabilité sociale est introduit à la fin des années 90 avec l'engagement de faire diminuer le taux élevé de chômage structurel. Dans la dernière partie, l'analyse comparative international propose une recomposition du cadre des divers contenus de la responsabilité sociale en partant de la grande question en débat dans les sociétés: établir l'engagement des entreprises pour une consolidation des contrats de travail en tant qu'élément de la citoyenneté sociale.

Mots-CLÉs: responsabilité sociale, entreprises, KEYwORDS: social responsibility, businesses, entreprises dans la société, Brésil et entreprises, Palavras-chave: responsabilidade social, businesses in the society, Brazil and businesses, culture des entreprises. empresas, empresas na sociedade, Brasil e business culture. empresas, cultura empresarial. 